\title{
Investigation of Springback Behavior of DP Series Sheet Metal in Bending Process
}

\author{
[Emin USLU, Gul TOSUN, Nihat TOSUN]
}

\begin{abstract}
In the study, the springback behavior took place during $V$ bending of DP series Sheet metals having different quality was experimentally investigated. For this purpose, sheet metal having quality of DP800 and DP600 with size of $45 \times 90$ $\mathrm{mm}$ thickness of $1,1.5$ and $2 \mathrm{~mm}$ and $\mathrm{V}$ bending die having 60 , 90 , and $120^{\circ}$ angles were used. The data obtained from results of experimental studies was graphically represented and the evaluated.
\end{abstract}

Keywords - : Springback, Sheet, V bending

\section{Introduction}

Sheet materials have been widely employed in many fields such as automotive, aerospace, utensils, machinery manufacturing, and construction area. The processing of the sheet material includes a variety of methods such as deep drawing, bending, drilling and cutting. There are many methods commonly used in processing such as $\mathrm{V}$ bending, $\mathrm{U}$ bending, edge bending and free bending. Bending process is the process in which material is shaped around an axis without waste removal process by heating or without heating material. Various failures might be encountered in bending process due to material properties and manufacturing. Measurement errors are one of these. Common error experienced in bending process is springback. By removing exerted force, the material tries to return the original state and partially elongates. Springback results from elasticity behavior of material is defined as the difference between bending angle of bended material and the true bending angle of material after it is processed. Springback is a processing problem consisted of many variables such as mechanical and chemical properties of sheet metal, processing factors, and dimensional parameter [1].

Springback brings about some troubles in installation of sheet metals and the installation of the material part has not been able to achieve properly. This means the disposal of the part to scrap, financial loses, and an increase in cost of product.

Emin USLU

Bayburt University, Engineering Faculty, Mechanical Engineering Bayburt, Turkey

Gul TOSUN

Firat University, Engineering Faculty, Mechanical Engineering Elazig, Turkey

Nihat TOSUN

Firat University, Engineering Faculty, Mechanical Engineering Elazig, Turkey
Thus it is very significant to pre-estimate springback and its control in order to eliminate or to reduce problem experienced during installation, to ensure exact dimension in terms of decreasing cost of die and manufacturing low-cost parts. For obtaining intended angle after bending and shaping of sheet metal, springback should be compensated.

Many methods are benefited to compensate the springback problem. There two fundamental methods, mainly numerical and experimental, in investigating bending and shaping sheet metal. The results provided by experimental methods forms true data.

When researches about springback are taken into consideration, Sriram et al. [2], experimental and theoretical comparison of $\mathrm{V}$ bending on sintered copper sheets were performed. Zhang et al. [3] investigated the amount of springback due to $\mathrm{V}$ die bending process of three different materials mainly steel, brass, and copper by carrying out a series of experimental studies. Micari et al. [4], analyzed springback effect some materials through three dimensional pressing. Aluminum with $6 \mathrm{~mm}$ thicknesses was employed as material and $\mathrm{V}$ die bending and $\mathrm{U}$ die bending process were also applied to it. Keum and Han [5], analyzed the effects of springback values of different aluminum alloys at various shaping temperatures after bending and found out that hot bending decreased the amount of bending. Esat et al. [6] numerically and experimentally investigated springback of aluminum having different thicknesses using different angled die and concluded that the springback was decreased for the materials. Moon et al. [7] investigated the effect of tool temperature on the springback of an aluminium 1050 sheet and showed that the combination of hot die and cold punch could improve the forming quality based on the preliminary experimental results of draw bending process. Yanagimoto et al. [8] performed a serial of hot and mild shaping experiments of sheet metal on high strength sheet metals and analyzed the effects of working temperature on shaping. Yenice [9] experimentally studied the amount of springback by bending of DP600, HSLA350, and Fe04 materials in $\mathrm{V}$ process in the direction of varied rolling with various radii at diverse angles. Garcia-Romeu ]10] researched springback behavior due to free $\mathrm{V}$ bending by tensile tests of stainless steel and aluminum sheet metal. Mori et al. [11] looked into the springback behavior of sheet metal having ultra-high strength using CNC press. Tekaslan et al. [12] designed a $\mathrm{V}$ die in order to determine the amount of springback and determined how much sheet metal with thicknesses of $0.75 \mathrm{~mm}$ can elongate at different angles. Osman et al. [13] suggests a methodology for the prediction of springback ratio in $\mathrm{V}$-die bending. They develop theoretical model for air bending using true strain and neutral fiber position that satisfy continuity of the radial stress. In a study performed by Kilic et al. [14] mechanical 
properties alteration of high strength DP800 sheet metal and springback behavior in bending process using $\mathrm{V}$-shaped die were investigated. Yilamu et al. [15] carried out a study on bending of aluminum sheet coated with stainless steel and determining springback resulted bending. Kim and Lee [16] analyzed the effects of remained austenite phase on springback of cold rolled TRIP steel sheet through a serial of $\mathrm{V}$ bending tests. Isiktas [1] designed a $\mathrm{V}$ bending die in order to determine the amount of springback of DKP and stainless sheet materials. Kagzi et al. [17] reported that springback is highly influenced by work hardening. So for accurate prediction of springback the work hardening must be taken in to account. Otu and Demirci [18] studied the effect of pre-stress on springback bending AA5754 and A11050, aluminum sheet materials, in V die with $60^{\circ}$. Singh and Kumar [19] investigated springback using effect of process parameters such as wall angle, tool diameter and step depth in the experiments conducted on AA 1200 H14 aluminum alloys.

According to results mentioned above, it has been predicted changing die angle depending on the amount of springback in order to decrease springback. For this purpose, springback graphics obtained by experimental studies is very beneficial. However, these kind of graphics in literature have been available for limited materials. In this study a serial of experimental studies in order to determine springback behavior of sheet materials using various parameters.

\section{Materials and Method}

In the study springback resulted from shaping of sheet materials having diverse quality by employing $\mathrm{V}$ bending process was researched depending on sheet material, sheet thickness, rolling direction, and die angle. Processing parameters were given in Table 1.

TABLO 1. PARAMETERS USED V DIE BENDING PROCESS

\begin{tabular}{|l|l|}
\hline Process parameter & Values \\
\hline Material & DP800, DP600 \\
\hline Thickness $(\mathrm{mm})$ & $1,1.5,2$ \\
\hline Rolling direction & Parallel, Perpendicular to rolling direction \\
\hline Die angle $\left(^{\circ}\right)$ & $60,90,120$ \\
\hline
\end{tabular}

DP800 and DP600, generally defined as high strength sheet metals, became inevitable materials for automotive industry especially in applications require high strength and superior handling due to their excellent performance. The chemical compositions of DP 600 and DP800 sheet metals used in the study were given in Table 2 while strength properties were given in Table 3 .

TABLE 2. CHEMICAL COMPOSITION OF SHEET MATERIALS

\begin{tabular}{|l|c|c|c|c|c|c|c|c|}
\hline Sample & $\mathbf{C}$ & $\mathbf{M n}$ & $\mathbf{P}$ & $\mathbf{S}$ & $\mathbf{S i}$ & $\mathbf{A l}$ & $\mathbf{N b}$ & $\mathbf{C r}$ \\
\hline DP600 & 0.09 & 1.60 & 0.015 & 0.004 & 0.18 & 0.02 & 0.015 & 0.12 \\
\hline DP800 & 0.12 & 1.50 & 0.013 & 0.002 & 0.20 & 0.04 & 0.015 & 0.02 \\
\hline
\end{tabular}

TABLE 3. STRENGTH PROPERTIES OF SHEET MATERIALS

\begin{tabular}{|l|c|c|c|}
\hline Material & $\begin{array}{c}\text { Maximum Tensile } \\
\text { Stress (MPa) }\end{array}$ & $\begin{array}{c}\text { Yield Stress } \\
\text { (MPa) }\end{array}$ & $\begin{array}{c}\text { Strain } \\
(\mathbf{\%})\end{array}$ \\
\hline DP800 & 808 & 512 & 18 \\
\hline DP600 & 612 & 396 & 24 \\
\hline
\end{tabular}

Dies used in $\mathrm{V}$ bending process manufactured from $\mathrm{St} 37$ steel material having dimensions indicated in Figure 1. Samples of sheet experiment were cut to have size of 90x45 $\mathrm{mm}$ considering rolling direction. For each case bending experiments were performed three times. Bending process was continued until the space between male and female die reached to the thickness of sheet material. The distance between dies should be the same as the thickness of sheet material to no effect springback behavior by crashing sheet material. As soon as the male die arrived the last point the load exerted on sheet was removed.
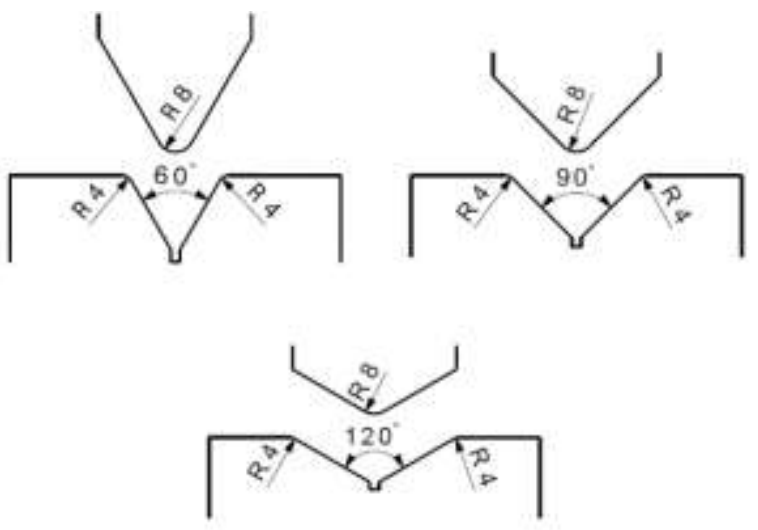

Fig 1. Dimensions of die used

After bending experiment were carried out, springback of sheet materials was measured by determining how much deviation from die angle occurred. After bending the samples bending angles were measured thanks to a digital goniometer.

\section{Result and Discussion}

Bending experiments were carried out depending on variable process parameters such as Quality, thickness, rolling direction and die angle. Bending process was applied to samples at 60,90 and $120^{\circ}$ die angles. From rolling direction indicated in results, $0^{\circ}$ imply directions parallel to rolling direction while $90^{\circ}$ defined direction perpendicular to rolling direction (Figure 2).
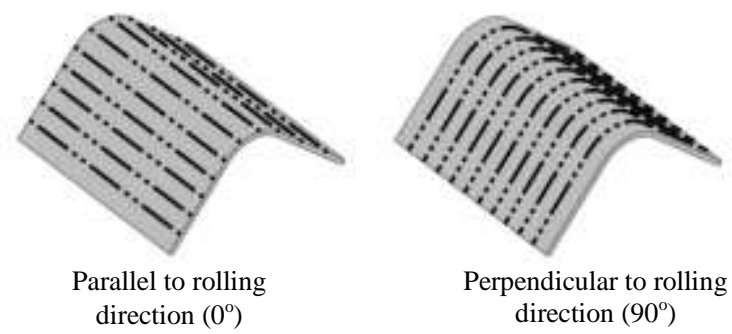

Fig 2. Illustration of rolling direction 
The amount of springback of DP600 steel sheet material was shown in Figure 3. It is evident from Figure 4 at die angles of 60,90 , and $120^{\circ}$ that springback happen to be positive for all thicknesses and for all rolling parameters i.e materials shown an opening out trend. However, the springback values happened to be positive way at all die angles, the lowest value was determined at $120^{\circ}$ while the highest value was determined at $60^{\circ}$ die angle. It is seen Springback values of samples of $1 \mathrm{~mm}$ thickness for all die angles were found to be the highest while it is the lowest value for samples of $2 \mathrm{~mm}$ thickness.
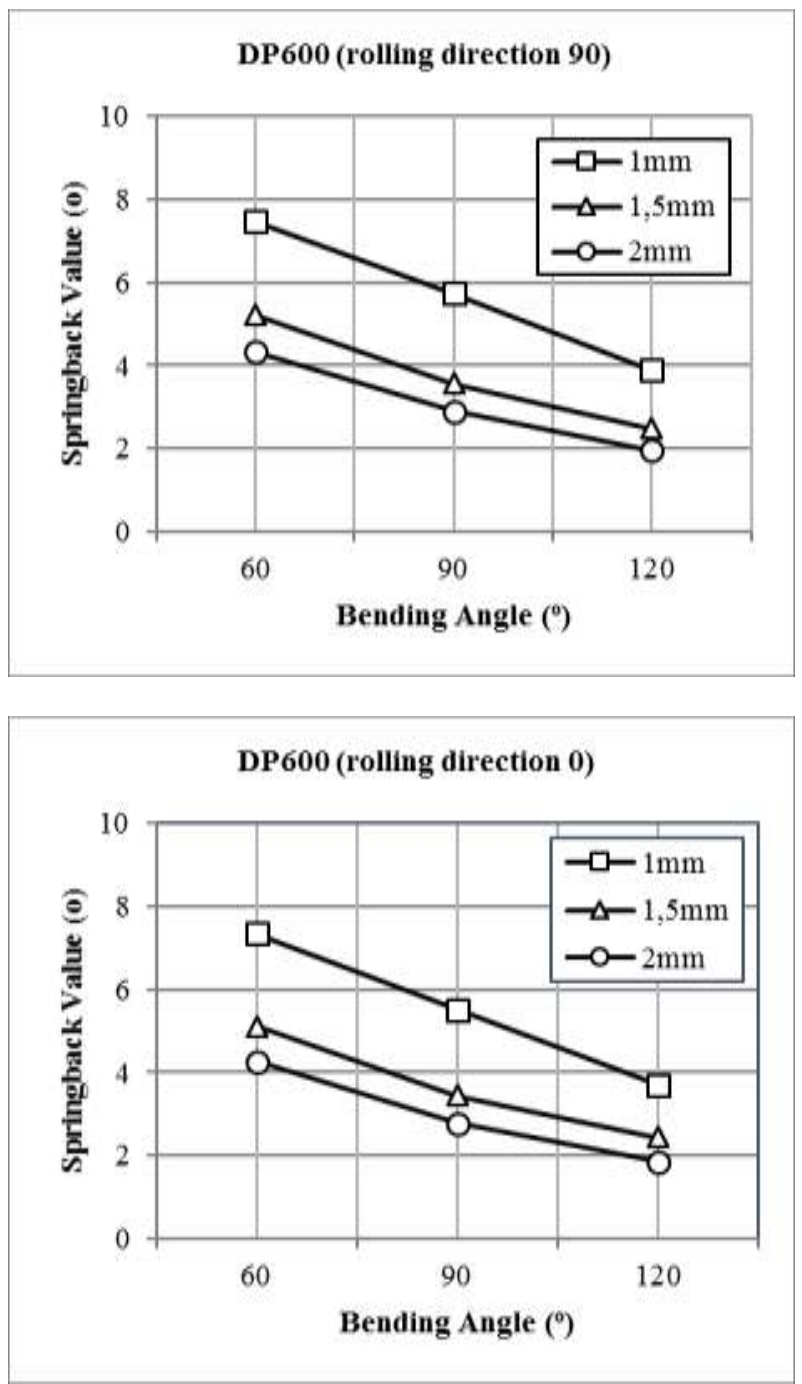

Fig 3. Springback behavior of DP600 sheet metal

Springback behavior of DP800 sheet material was illustrated in Figure 4. It is clear from Figure that springback values behaved in a positive way for all die angles, for sample thicknesses and for all rolling direction parameters i.e shown an opening out tendency. It is found out that springback values of samples bended in die angle of $60^{\circ}$ were bigger than ones of samples bended at $90^{\circ}$ an $120^{\circ}$ die angles and the lowest springback values were obtained for samples bended at $120^{\circ}$ die angle. When springback behavior considered in terms of thickness of sheet material, the highest springback value obtained for sample with thicknesses of $1 \mathrm{~mm}$ while the lowest springback value was determined for samples of $2 \mathrm{~mm}$ thicknesses.
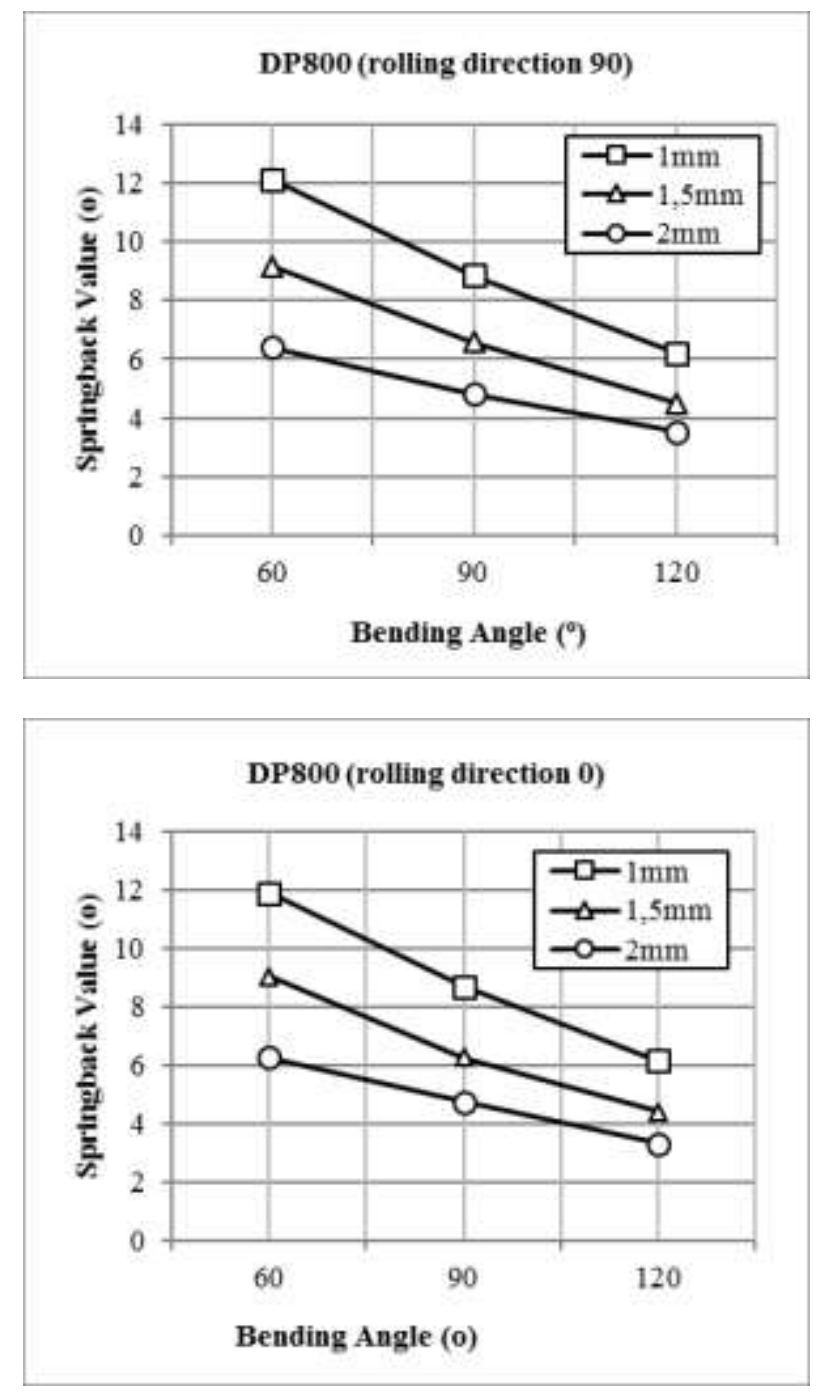

Fig 4. Springback behavior of DP800 sheet metal

When Figure 3 and Figure 4 were analyzed, it was seen that amount of springback was decreased as the die angle increased in case all other parameters were constant [20]. While the highest springback value was obtained at die angle of $60^{\circ}$, the lowest value was obtained for $120^{\circ}$ die angle. For example, in result of bending process of DP800 sheet material with thickness of $1 \mathrm{~mm} 12.1^{\circ}, 8.85^{\circ}$ and $6.22^{\circ}$ at angles $60^{\circ}, 90^{\circ}$ and $120^{\circ}$ respectively. The reason of decrease in springback with increasing die angle can be explained by the decrease in elongation and deformation occurred on the outer face of sheet metal [20]. In Figure 5, the dark parts show region undergone deformation and these region is reduced from $60^{\circ}$ to $120^{\circ}$.

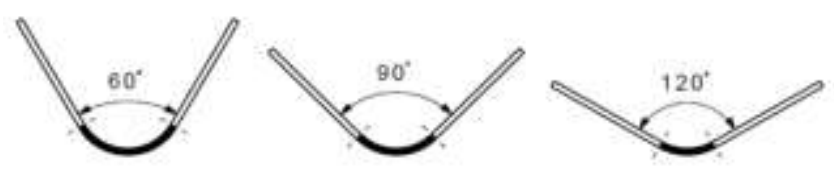

Fig 5. Illustration of deformed regions 
It is clear from Figure 3 and 4 that amount of springback is decreased as the thickness of sheet materials is increased $[21,22]$. While the highest value obtained for sample having thickness of $1 \mathrm{~mm}$, the lowest value obtained for sample having thickness of $2 \mathrm{~mm}$. For instance, as a result of bending process of DP600 chosen to be perpendicular to rolling direction, it was found to be $7.45^{\circ}, 5.21^{\circ}$ and $4.32^{\circ}$ for samples having thicknesses of $1,1.5$, and $2 \mathrm{~mm}$, respectively. Moreover, the results are in good agreement with the inverse proportionality between springback and thickness $(\mathrm{K}=\mathrm{R} / \mathrm{t})$ [18]. The reason of springback decrease with increase in thickness can be stated as decrease in the remained tensile occurred in bending region [23].

As Forming limit diagrams (FLDs) is increase formability is improved. Capan [24] said that as the thickness of sheet material was increased, FLDs was risen. As a result of improving formability with increase in thickness, it can be said amount of springback is decreased.

It was shown that springback results are almost same in bending process parallel to the rolling direction and perpendicular to the rolling direction under same conditions for Sheet materials used in experiments. Therefore, only results of bending perpendicular to the rolling direction was considered in interpretation given below. For example, in the result of applying bending process of $60^{\circ}$ die angle to the DP600 sheet material with thickness of $1 \mathrm{~mm}$, amount of springback was determined $7.45^{\circ}$ for perpendicular case and $7.33^{\circ}$ for parallel case.

In the result of applying bending perpendicular to the rolling direction, the effects of material quality on springback behavior was shown in Figure 6.

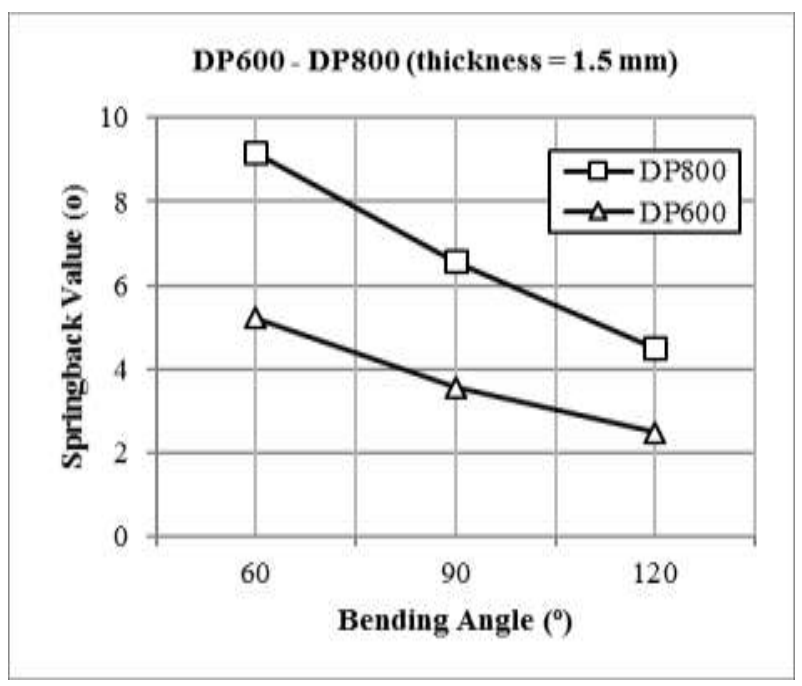

Fig 6. Comparison of springback behaviors of DP600 and DP800 sheet metals

When Figure 7 is analyzed it is found that DP800 steel sheet exhibited the highest springback behavior. Because yield strength of DP800 is higher than DP600 material, it is clear from Figure 7 and Table 3, its amount of springback behavior is also higher.

This means that from Figure 6 it was determined that amount of springback is high for materials having higher yield strength while it is low for materials having lower yield strength $[1,6]$.

\section{Conclusion}

As a result of studies performed, it was determined that springback behavior changed depending on die and material parameters. It was found that amount springback is decreased with increase in die angle. The reason can be explained by the decrease in elongation and deformation formed on outer surface. Depending on material quality springback behavior varies. while in materials with low yield strength springback formation is rare, it is common in materials with high yield strength. It was determined that amount of springback decreased with increase in thicknesses. Moreover, this case verifies that springback is inversely proportional to the thickness $(\mathrm{K}=\mathrm{R} / \mathrm{t})$. During designing, Designer can compensate springback problem in bending process by fixing dies in opposite way as much as the springback obtained by studies.

\section{References}

[1] Isiktas, A., 2011. Examining the springback of DKP and stainless steel sheets with different thickness in the V-bending process carried out in different angles, Master's Thesis, Balıkesir University, Institute of Science, Balıkesir. (in Turkish)

[2] Sriram, S., Jothi, N., Kumar, N.L.L.N. and Venugopal, P., 1997. Vbending studies on sintered copper powder metallurgical preform sheets, Journal of Materials Processing Technology, 70, 156-162.

[3] Zhang, L.C., Lu, G. and Leong, S.C., 1997. V-shaped sheet forming by deformable punches, Journal of Materials Processing Technology, 63, 134-139.

[4] Micari, F., Forcellese, A., Fratini, L., Gabrielli, F. and Alberti, N., 1997. Springback evaluation in fully 3-D sheet metal forming processes, CIRP Annals - Manufacturing Technology, 46, 1, 167170 .

[5] Keum Y.T. and Han B.Y., 2002. Springback of FCC sheet in warm forming, Journal of Ceramic Processing Research, 3(3), 159-165.

[6] Esat, V., Darendeliler, H. and Gokler, M.I., 2002. Finite element analysis of springback in bending of aluminium sheets, Materials and Design, 23, 223-229.

[7] Moon H., Kang S.S., Cho J. R., and Kim T.G., 2003. Effect of tool temperature on the reduction of the springback of aluminum sheets, Journal of Materials Processing Technology, 132(1-3), 365-368.

[8] Yanagimoto, J., Oyamada, K. and Nakagawa, T., 2005. Springback of high-strength steel after hot and warm sheet formings, CIRP Annals-Manufacturing Technology, 54, 213-216.

[9] Yenice, M.M., 2006. Investigation of springback behavior in sheet metals forming by bending, Master's Thesis, Uludag University, Institute of Science, Bursa. (in Turkish)

[10] Garcia-Romeu, M.L., Ciurana, J. and Ferrer, I., 2007. Springback determination of sheet metals in an air bending process based on an experimental work, Journal of Materials Processing Technology, $191,174-177$.

[11] Mori, K., Akita, K. and Abe, Y., 2007. Springback behaviour in bending of ultra-high-strength steel sheets using CNC servo pres, International Journal of Machine Tools \& Manufacture, 47, 321325 .

[12] Tekaslan, O., Seker. U. and Gerger, N., 2007. Determining springback amount of steel sheet metal have $0.75 \mathrm{~mm}$ thickness in 
bending dies sheet materials, Journal of Engineering Sciences, Pamukkale University, 13, 15-22. (in Turkish)

[13] Osman M.A., Shazly M., El-Mokaddem A. and Wifi A.S., 2010. Springback prediction in V-die bending: modelling and experimentation, Journal of Achievements in Materials and Manufacturing Engineering, 38(2), 179 - 186.

[14] Kilic, S., Ozturk, F. and Toros, S., 2009. Investigation of mechanical properties and springback behavior of DP800 steel, Machine Design and Manufacturing Journals, 11, 1, 40-45. (in Turkish)

[15] Yilamu, K., Hino, R., Hamasaki, H. and Yoshida, F., 2010. Air bending and springback of stainless steel clad aluminum sheet, Journal of Materials Processing Technology, 210, 272-278.

[16] Kim, S. and Lee, Y., 2011. Effect of retained austenite phase on springback of cold-rolled TRIP steel sheets, Materials Science and Engineering A, 530, 218-224.

[17] Kagzi S.A., Gandhi A.H. and Raval H.K., 2012. Effect of Material Properties on Springback of Layered Strip: An Analytical Study. Proceeding of 1st national conference on TFMS, Surat, pp 398-402.

[18] Otu, R. and Demirci H.I., 2012. Determination of amount springback of AA5754 and Al1050 sheet materials by using different bending methods in bending with $60^{\circ} \mathrm{V}$-die. International Iron \& Steel Symposium, Karabuk, Turkey, 02-04 April. (in Turkish)

[19] Singh P. and Kumar N., 2015. Experimental and Statistical Study on Springback Behavior in Incremental Sheet Metal Forming Process, International Journal of Innovative Research in Science, Engineering and Technology, 4(9), 8125-8130.

[20] Ozdemir A., 2010. Determination with experimental and finite elements of springback behavior in sheet metals and estimation of its with artificial neural network. Master's Thesis, Gazi University, Institute of Science, Ankara. (in Turkish)

[21] Fei, D. and Hodgson, P., 2006. Experimental and numerical studies of springback in air v-bending process for cold rolled TRIP steels, Nuclear Engineering and Design, 236, 1847-1851.

[22] Kilic, S., 2009. İnvestigation of springback behaviour of DP600 steel, Master's Thesis, Nigde University, Institute of Science, Nigde. (in Turkish)

[23] Livatyal1, H., and Altan, T., 2001. Prediction and elimination of springback in straight flanging using computer aided design methods Part 1. Experimental investigations, Journal of Materials Processing Technology, 117, 262-268.

[24] Capan, L., 2003. Plastic Forming of Metals, Caglayan Publishing House, Istanbul. (in Turkish) 